\title{
Article
}

\section{Differences in Atrial Remodeling in Hypertrophic Cardiomyopathy Compared to Hypertensive Heart Disease and Athletes' Hearts}

Helge Servatius ${ }^{1, *,+} \mathbb{D}$, Simon Raab ${ }^{1,+}$, Babken Asatryan ${ }^{1} \mathbb{D}$, Andreas Haeberlin ${ }^{1}$, Mattia Branca ${ }^{2} \mathbb{D}$, Stefano de Marchi ${ }^{1}{ }^{(D}$, Nicolas Brugger ${ }^{1}{ }^{(D)}$, Nikolas Nozica ${ }^{1}$, Eleni Goulouti ${ }^{1}$, Elena Elchinova ${ }^{1}$, Anna Lam ${ }^{1}(\mathbb{D}$, Jens Seiler ${ }^{1}$, Fabian Noti ${ }^{1}$, Antonio Madaffari ${ }^{1}{ }^{\mathbb{D}}$, Hildegard Tanner ${ }^{1}$, Samuel H. Baldinger ${ }^{1}$, Tobias Reichlin ${ }^{1}{ }^{1 D}$, Matthias Wilhelm ${ }^{1}$ and Laurent Roten ${ }^{1}$ (D)

Citation: Servatius, H.; Raab, S.; Asatryan, B.; Haeberlin, A.;

Branca, M.; de Marchi, S.; Brugger, N.; Nozica, N.; Goulouti, E.; Elchinova, E.; et al. Differences in Atrial Remodeling in Hypertrophic Cardiomyopathy Compared to Hypertensive Heart Disease and Athletes' Hearts. J. Clin. Med. 2022, 11, 1316. https://doi.org/10.3390/ jcm11051316

Academic Editor: Michele Correale

Received: 1 February 2022

Accepted: 23 February 2022

Published: 27 February 2022

Publisher's Note: MDPI stays neutral with regard to jurisdictional claims in published maps and institutional affiliations.

Copyright: (C) 2022 by the authors. Licensee MDPI, Basel, Switzerland. This article is an open access article distributed under the terms and conditions of the Creative Commons Attribution (CC BY) license (https:// creativecommons.org/licenses/by/ $4.0 /)$
1 Department of Cardiology, Inselspital, Bern University Hospital, University of Bern, 3010 Bern, Switzerland; simon.raab@gmx.ch (S.R.); babken.asatryan@insel.ch (B.A.); andreas.haeberlin@insel.ch (A.H.); stefano.demarchi@insel.ch (S.d.M.); nicolas.brugger@insel.ch (N.B.); nikolas.nozica@insel.ch (N.N.); eleni.goulouti@insel.ch (E.G.); elenageorgieva.elchinova@insel.ch (E.E.); annalam@gmx.ch (A.L.); jens.seiler@insel.ch (J.S.); fabian.noti@insel.ch (F.N.); antonio.madaffari@insel.ch (A.M.); hildegard.tanner@insel.ch (H.T.); samuel.baldinger@insel.ch (S.H.B.); tobias.reichlin@insel.ch (T.R.); matthias.wilhelm@insel.ch (M.W.); laurent.roten@insel.ch (L.R.)

2 CTU Bern, University of Bern, 3010 Bern, Switzerland; mattia.branca@ctu.unibe.ch

* Correspondence: helge.servatius@insel.ch; Tel.: +41-31-664-17-01

$\dagger$ These authors have contributed equally to this work.

\begin{abstract}
Background: Hypertrophic cardiomyopathy (HCM), hypertensive heart disease (HHD) and athletes' heart share an increased prevalence of atrial fibrillation. Atrial cardiomyopathy in these patients may have different characteristics and help to distinguish these conditions. Methods: In this single-center study, we prospectively collected and analyzed electrocardiographic (12-lead ECG, signal-averaged ECG (SAECG), $24 \mathrm{~h}$ Holter ECG) and echocardiographic data in patients with HCM and HHD and in endurance athletes. Patients with atrial fibrillation were excluded. Results: We compared data of 27 patients with HCM (70\% males, mean age $50 \pm 14$ years), 324 patients with HHD (52\% males, mean age $75 \pm 5.5$ years), and 215 endurance athletes $(72 \%$ males, mean age $42 \pm 7.5$ years). HCM patients had significantly longer filtered P-wave duration (153 $\pm 26 \mathrm{~ms})$ and PR interval (191 $\pm 48 \mathrm{~ms}$ ) compared to HHD patients $(144 \pm 16 \mathrm{~ms}, p=0.012$ and $178 \pm 31, p=0.034$ respectively) and athletes (134 $\pm 14 \mathrm{~ms}, p=0.001$ and $165 \pm 26 \mathrm{~ms}$, both $p<0.001$, respectively). HCM patients had a mean of $4.9 \pm 16$ premature atrial complexes per hour. Premature atrial complexes per hour were significantly more frequent in HHD patients $(27 \pm 86, p<0.001)$, but not in athletes $(2.7 \pm 23, p=0.639)$. Left atrial volume index (LAVI) was $43 \pm 14 \mathrm{~mL} / \mathrm{m}^{2}$ in $\mathrm{HCM}$ patients and significantly larger than age- and sex-corrected LAVI in HHD patients $30 \pm 10 \mathrm{~mL} / \mathrm{m}^{2} ; p<0.001$ ) and athletes $\left(31 \pm 9.5 \mathrm{~mL} / \mathrm{m}^{2} ; p<0.001\right)$. A borderline interventricular septum thickness $\geq 13 \mathrm{~mm}$ and $\leq 15 \mathrm{~mm}$ was found in 114 (35\%) HHD patients, $12(6 \%)$ athletes and $3(11 \%)$ HCM patients. Conclusions: Structural and electrical atrial remodeling is more advanced in HCM patients compared to HHD patients and athletes.
\end{abstract}

Keywords: athlete's heart; left ventricular hypertrophy; atrial cardiomyopathy; signal-averaged ECG; P-wave duration; LAVI

\section{Introduction}

Left ventricular hypertrophy is a proportional reaction of heart muscle cells to increased loading conditions, in patients with long-standing arterial hypertension or in long-term endurance athletes, leading to hypertensive heart disease (HHD) and athlete's heart, respectively. Left ventricular hypertrophy disproportional to loading conditions 
occurs in patients with hypertrophic cardiomyopathy (HCM). Pathogenic variants in sarcomeric genes underlie nearly $65 \%$ of $\mathrm{HCM}$ cases, and in the vast majority are transmitted as an autosomal dominant trait [1-7]. Hypertrophic cardiomyopathy is diagnosed in the presence of left ventricular wall thickness $\geq 15 \mathrm{~mm}$ detected by any imaging technique $[1,5,8]$. In addition to structural features, electrocardiographic abnormalities are identified in $90 \%$ of HCM patients [9-11]. However, distinguishing HCM from other forms of left ventricular hypertrophy can be difficult because of the lack of specific electrocardiographic and echocardiographic diagnostic parameters, particularly when the interventricular wall thickness (IVS) is $>12 \mathrm{~mm}$ in athletes or in patients with $\operatorname{HHD}[1,5,9,12]$.

Left ventricular hypertrophy increases left atrial wall stress by several mechanisms, thereby promoting atrial cardiomyopathy and ultimately atrial fibrillation. HHD, HCM and athlete's heart have all been associated with an increased prevalence of atrial fibrillation $[13,14]$. Structural alterations in patients with HCM affect both the ventricular myocardium and the atrial myocardium, and hemodynamic strain imposed on the atria by the abnormal ventricular loading conditions further promotes atrial remodeling in patients with HCM [15-17]. In athletes, cumulative training hours and repetitive episodes of high atrial volume load increase atrial wall stress and atrial remodeling [18].

The aim of this study was to compare electrocardiographic (12-lead ECG, signalaveraged ECG (SAECG), $24 \mathrm{~h}$ Holter ECG) and echocardiographic parameters of atrial and LV function in patients with HCM, HHD and athletes.

\section{Methods}

In this prospective observational investigator-initiated study, three different patient populations were prospectively enrolled (see details below). The Cantonal Ethics Committee of Bern, Switzerland, approved the study protocol and all participants provided written informed consent. The following exclusion criteria were applied: atrial fibrillation or atrial flutter, manifest ventricular pre-excitation, severe pulmonary hypertension, severe mitral valve disease, mechanical valve replacements, acute coronary syndrome, major cardiac surgery or hospitalization due to heart failure within the previous 3 months, atrial stimulation by either a pacemaker (PM) or an implantable cardioverter defibrillator (ICD), heart transplantation and incapacity to provide written informed consent.

\subsection{Hypertrophic Cardiomyopathy Patient Population}

Patients with HCM were enrolled in the outpatient HCM clinic. The diagnosis of HCM was based on internationally accepted criteria [1].

\subsection{Hypertensive Heart Disease Patient Population}

As a first comparison group, we used subjects with arterial hypertension and left ventricular hypertrophy included in the prospective STAR-FIB cohort study. Left ventricular hypertrophy was defined as a left ventricular myocardial mass index above normal range according to the published criteria ( $\geq 102 \mathrm{~g} / \mathrm{m}^{2}$ in males and $\geq 88 \mathrm{~g} / \mathrm{m}^{2}$ in females) [19]. The STAR-FIB cohort study was an atrial fibrillation screening study that included 795 patients without atrial fibrillation, aged $65-84$ years $[20,21]$.

\subsection{Endurance Athlete Population}

As a second comparison group, we used non-elite marathon runners included in two prospective, cross-sectional observational studies [22,23]. We performed the same, prospective examinations in all athletes as in patients with HCM, except for ambulatory $24 \mathrm{~h}$ Holter ECG, which we only performed in a subset of athletes, and laboratory examinations, which were not performed in athletes. We excluded athletes with hypertension (blood pressure $\geq 140 / 90 \mathrm{mmHg}$ ), a history of cardiovascular diseases, atrial fibrillation or atrial flutter. 


\subsection{Patient Work-Up}

All patients from all 3 groups underwent the same baseline examination, including a comprehensive medical history, determination of heart rate and blood pressure at rest, 12-lead ECG, SAECG of the P wave and of the QRS complex, $24 \mathrm{~h}$ Holter monitoring, transthoracic echocardiography and laboratory analysis including high-sensitivity C-reactive protein (hsCRP), brain natriuretic peptide (BNP) and high-sensitivity Troponin $\mathrm{T}$ (hsTnT). ECGs and SAECGs were recorded with patients in a supine position at a sweep speed of $25 \mathrm{~mm} / \mathrm{s}$ (MAC5500, GE Healthcare, Chicago, IL, USA). Methods for recording and analyzing the signal-averaged $P$ wave have been described previously $[24,25]$. In brief, we recorded three bipolar orthogonal leads, referred to as the $\mathrm{x}, \mathrm{y}$ and $\mathrm{z}$ leads, in a room without electrical interferences. Measurements computed by the system included filtered P-wave duration, root-mean-square voltage of the terminal 40, 30 and 20 milliseconds, root-mean-square voltage of the $\mathrm{P}$ wave and the P-wave integral (area under the vector magnitude curve from P-wave onset to offset). We performed standard transthoracic echocardiography (Vivid E95, GE Healthcare, Chicago, IL, USA) according to the recommendations of the European Association of Echocardiography [26]. The left ventricular ejection fraction (LVEF), dimensions and wall thickness as well as left atrial diameter and mono- and biplane-volume were determined in the parasternal long-axis view, 4- and 2-chamber view, as appropriate. The mitral valve inflow pattern was determined by pulsedwave Doppler (E/A ratio; deceleration time). Myocardial velocities were recorded using Doppler tissue imaging with the sample volume placed at the lateral mitral annulus in the 4-chamber view.

In all patients, we recorded an ambulatory $24 \mathrm{~h}$ Holter ECG (Lifecard CF, Spacelabs Healthcare, Snoqualmie, WA, USA) and manually analyzed and interpreted the data using the Pathfinder SL software (Spacelabs Healthcare, Snoqualmie, WA, USA).In the $24 \mathrm{~h}$ ECG we counted the number of premature atrial complexes, defined as a reduction in the RR interval of $\geq 25 \%$ compared to the previous normal RR interval and with normal QRS morphology. We assessed the minimal RR coupling interval as well as the relative reduction in the coupling interval from the previous normal $R R$ interval (coupling interval index (CI-index)).

\section{Statistical Analysis}

Continuous variables are expressed as means with standard deviations, and categorical variables as numbers with percentages. Continuous variables were compared using the Mann-Whitney $U$ test or t-test in the case of two-group comparison. Differences in proportions were tested with Pearson's $\chi^{2}$ test or Fisher's exact test, as appropriate. Uniand multivariable linear regression analysis was conducted to assess the effect of age, sex and group assignment (HCM, HHD and athletes) on the following variables: filtered P-wave duration, PACS count, PR interval, LAVI and BNP. To predict underlying heart disease in patients with HCM and in patients with HHD and an interventricular septum thickness $\geq 13 \mathrm{~mm}$, a receiver operating characteristic (ROC) analysis was performed to identify cut-off values for variables, which appeared to be different among the groups. The following variables were analyzed: filtered P-wave duration, LAVI, left ventricular end-diastolic diameter and thickness of the interventricular septum. We did not perform this kind of analysis in athletes with an interventricular septum thickness $\geq 13 \mathrm{~mm}$ because of the low number of subjects in this group $(n=12)$. All tests were performed at a two-sided $5 \%$ significance level with $95 \%$ confidence intervals (CIs). All analyses were performed using Stata 16.1 (StataCorp. Stata Statistical Software: Release 16. College Station, TX, USA: StataCorp LLC).

\section{Results}

We included $27 \mathrm{HCM}$ patients in the study ( $30 \%$ female; mean age $50 \pm 14$ years). These patients were compared to 324 patients with HHD ( $48 \%$ female; mean age $75 \pm 5.5$ years) and to 215 non-elite marathon runners ( $28 \%$ female; mean age $42 \pm 7.5$ years). Table 1 
shows baseline patient characteristics of the three groups. HCM patients were significantly older than athletes and significantly younger than HHD patients (both $p$ values $<0.001$ ). The interventricular septum was thicker in HCM patients compared to athletes and HHD patients (Table 1 and Figure $1, p<0.001$ ), and the left ventricular end-diastolic diameter was smaller in HCM patients compared to HHD patients and athletes (Table 1 and Figure 2, $p<0.001)$. In the HHD group 114 patients (35\%) and in the athlete group 12 subjects $(6 \%)$ had an interventricular septum thickness of $\geq 13 \mathrm{~mm}$ (IVS13; Figure 1).

Table 1. Patient characteristics.

\begin{tabular}{|c|c|c|c|c|c|}
\hline & $\begin{array}{l}\mathrm{HCM} \\
n=27\end{array}$ & $\begin{array}{c}\text { HHD } \\
n=324\end{array}$ & $p$ Value * & $\begin{array}{c}\text { Athletes } \\
n=215\end{array}$ & $p$ Value ** \\
\hline \multicolumn{6}{|l|}{ Clinical characteristics } \\
\hline Age, years & $50 \pm 14$ & $75 \pm 5.5$ & $<0.001$ & $42 \pm 7.5$ & $<0.001$ \\
\hline Sex, female & $8(30 \%)$ & $155(48 \%)$ & 0.074 & $61(28 \%)$ & 1.000 \\
\hline BMI, $\mathrm{kg} / \mathrm{m}^{2}$ & $27 \pm 4.8$ & $28 \pm 4.4$ & 0.667 & $22 \pm 2.2$ & $<0.001$ \\
\hline Arterial hypertension & $10(37 \%)$ & $324(100 \%)$ & $<0.001$ & $\begin{array}{c}-2.2 \\
-\end{array}$ & - \\
\hline Diabetes mellitus & $4(15 \%)$ & $85(26 \%)$ & 0.012 & - & - \\
\hline Dyslipidemia & $11(41 \%)$ & $209(65 \%)$ & 0.269 & - & - \\
\hline Coronary artery disease & $2(7 \%)$ & $134(41 \%)$ & $<0.001$ & - & - \\
\hline Congestive heart failure & - & $9(3 \%)$ & 1.000 & - & - \\
\hline $\begin{array}{l}\text { Previous thrombotic event } \\
\text { Medication }\end{array}$ & $2(7 \%)$ & $57(18 \%)$ & 0.282 & - & - \\
\hline Betablocker & $14(52 \%)$ & $155(48 \%)$ & 0.842 & - & - \\
\hline Calcium channel blocker & $9(33 \%)$ & $99(31 \%)$ & 0.831 & - & - \\
\hline ACE inhibitors & $5(19 \%)$ & $97(30 \%)$ & 0.272 & - & - \\
\hline ARB & $3(11 \%)$ & $133(41 \%)$ & 0.002 & - & - \\
\hline Aldactone & $1(4 \%)$ & $10(3 \%)$ & 0.602 & - & - \\
\hline Diuretics & $4(15 \%)$ & $95(29 \%)$ & 0.121 & - & - \\
\hline Statins & $10(37 \%)$ & $200(62 \%)$ & 0.013 & - & - \\
\hline \multicolumn{6}{|l|}{ ECG } \\
\hline Heart rate, bpm & $63 \pm 11$ & $67 \pm 11$ & 0.042 & $55 \pm 7.8$ & $<0.001$ \\
\hline PR interval, $\mathrm{ms}$ & $191 \pm 48$ & $178 \pm 31$ & 0.034 & $165 \pm 26$ & $<0.001$ \\
\hline QRS width, ms & $110 \pm 27$ & $97 \pm 20$ & 0.002 & $95 \pm 10$ & $<0.001$ \\
\hline QTc, ms & $448 \pm 27$ & $439 \pm 24$ & 0.059 & $414 \pm 23$ & $<0.001$ \\
\hline \multicolumn{6}{|l|}{24 h Holter ECG } \\
\hline Minimal heart rate, beats per minute & $54 \pm 8.4$ & $54 \pm 7.6$ & 0.570 & $45 \pm 6.3$ & $<0.001$ \\
\hline Number of PACs per hour & $4.9 \pm 16$ & $27 \pm 86$ & $<0.001$ & $2.7 \pm 23$ & 0.639 \\
\hline \multicolumn{6}{|l|}{ SAECG } \\
\hline Filtered P-wave duration, ms & $153 \pm 26$ & $144 \pm 16$ & 0.012 & $134 \pm 14$ & $<0.001$ \\
\hline RMS voltage of $P$ wave, $\mu \mathrm{V}$ & $7.5 \pm 2.4$ & $6.4 \pm 2.3$ & 0.018 & $7.7 \pm 2.6$ & 0.648 \\
\hline P-wave integral, $\mu \mathrm{Vs}$ & $850 \pm 272$ & $672 \pm 235$ & $<0.001$ & $773 \pm 260$ & 0.153 \\
\hline RMS voltage of terminal $20 \mathrm{~ms}, \mu \mathrm{V}$ & $3.8 \pm 1.4$ & $4.3 \pm 2.4$ & 0.320 & $4.6 \pm 2.2$ & 0.073 \\
\hline RMS voltage of terminal $30 \mathrm{~ms}, \mu \mathrm{V}$ & $3.9 \pm 1.3$ & $4.3 \pm 2.4$ & 0.332 & $4.7 \pm 2.3$ & 0.073 \\
\hline RMS voltage of terminal $40 \mathrm{~ms}, \mu \mathrm{V}$ & $5.2 \pm 1.8$ & $5.5 \pm 8.6$ & 0.878 & $5.7 \pm 2.7$ & 0.330 \\
\hline \multicolumn{6}{|l|}{ Laboratory } \\
\hline $\mathrm{BNP}, \mathrm{pg} / \mathrm{mL}$ & $142 \pm 126$ & $84 \pm 93$ & 0.002 & - & - \\
\hline hsTNT, $\mu \mathrm{g} / \mathrm{L}$ & $0.02 \pm 0.02$ & $0.01 \pm 0.02$ & 0.391 & - & - \\
\hline hsCRP, mg/L & $2.8 \pm 4.0$ & $3.1 \pm 3.9$ & 0.726 & - & - \\
\hline \multicolumn{6}{|l|}{ Echocardiography } \\
\hline LVEF, \% & $66 \pm 7.0$ & $61 \pm 6.9$ & $<0.001$ & $65 \pm 5.3$ & 0.475 \\
\hline LVEDD, $\mathrm{mm}$ & $44 \pm 6.4$ & $49 \pm 6.3$ & $<0.001$ & $50 \pm 4.9$ & $<0.001$ \\
\hline IVS, $\mathrm{mm}$ & $18 \pm 3.4$ & $12 \pm 2.2$ & $<0.001$ & $10 \pm 1.5$ & $<0.001$ \\
\hline $\mathrm{PW}, \mathrm{mm}$ & $11 \pm 3.3$ & $11 \pm 1.9$ & 0.318 & $10 \pm 1.3$ & $<0.001$ \\
\hline LVMI, $\mathrm{g} / \mathrm{m}^{2}$ & $154 \pm 56$ & $133 \pm 30$ & 0.003 & $99 \pm 20$ & $<0.001$ \\
\hline RVD, mm & $32 \pm 5.7$ & $32 \pm 4.5$ & 0.947 & $36 \pm 3.8$ & $<0.001$ \\
\hline RV TDI S, cm $/ \mathrm{s}$ & $13 \pm 2.8$ & $13 \pm 3.1$ & 0.230 & $14 \pm 2.1$ & 0.001 \\
\hline RV diastolic area, $\mathrm{cm}^{2}$ & $18 \pm 3.5$ & $17 \pm 4.6$ & 0.280 & $23 \pm 3.6$ & $<0.001$ \\
\hline LAVI, $\mathrm{ml} / \mathrm{m}^{2}$ & $43 \pm 14$ & $30 \pm 10$ & $<0.001$ & $31 \pm 9.5$ & $<0.001$ \\
\hline E wave, $\mathrm{cm} / \mathrm{s}$ & $71 \pm 20$ & $67 \pm 20$ & 0.353 & $77 \pm 13$ & 0.042 \\
\hline A wave, $\mathrm{cm} / \mathrm{s}$ & $62 \pm 25$ & $87 \pm 20$ & $<0.001$ & $51 \pm 12$ & $<0.001$ \\
\hline $\mathrm{E}$ wave/A wave ratio & $1.4 \pm 1.0$ & $0.8 \pm 0.3$ & $<0.001$ & $1.6 \pm 0.4$ & 0.123 \\
\hline Isovolumetric relaxation time, $\mathrm{ms}$ & $101 \pm 13$ & $97 \pm 23$ & 0.501 & $84 \pm 13$ & $<0.001$ \\
\hline E deceleration time, $\mathrm{ms}$ & $222 \pm 60$ & $259 \pm 66$ & 0.006 & $175 \pm 29$ & $<0.001$ \\
\hline E wave TDI, $\mathrm{cm} / \mathrm{s}$ & $5.8 \pm 1.8$ & $5.7 \pm 1.6$ & 0.722 & $10 \pm 1.8$ & $<0.001$ \\
\hline E wave/E wave TDI ratio & $14 \pm 10$ & $12 \pm 4.5$ & 0.144 & $7.5 \pm 1.5$ & $<0.001$ \\
\hline A wave TDI, $\mathrm{cm} / \mathrm{s}$ & $7.2 \pm 2.1$ & $10 \pm 2.2$ & $<0.001$ & $8.7 \pm 1.7$ & $<0.001$ \\
\hline
\end{tabular}

Shown are numbers with percentages in parentheses, or means \pm standard deviations, as appropriate. ${ }^{*}$ Comparing HCM versus HHD patients. ** Comparing HCM patients versus athletes. ACE: angiotensin converting enzyme; ARB: angiotensin receptor blocker; BMI: body mass index; BP: blood pressure; CAD: coronary artery disease; CCB: calcium channel blocker; ECG: electrocardiogram; HCM: hypertrophic cardiomyopathy; HHD: hypertensive heart disease; PACS: premature atrial contractions; RMS: root-mean-square; SAECG: signal-averaged ECG; PW: posterior wall; LVMI: left ventricular mass index; RVD: right ventricular diameter. 


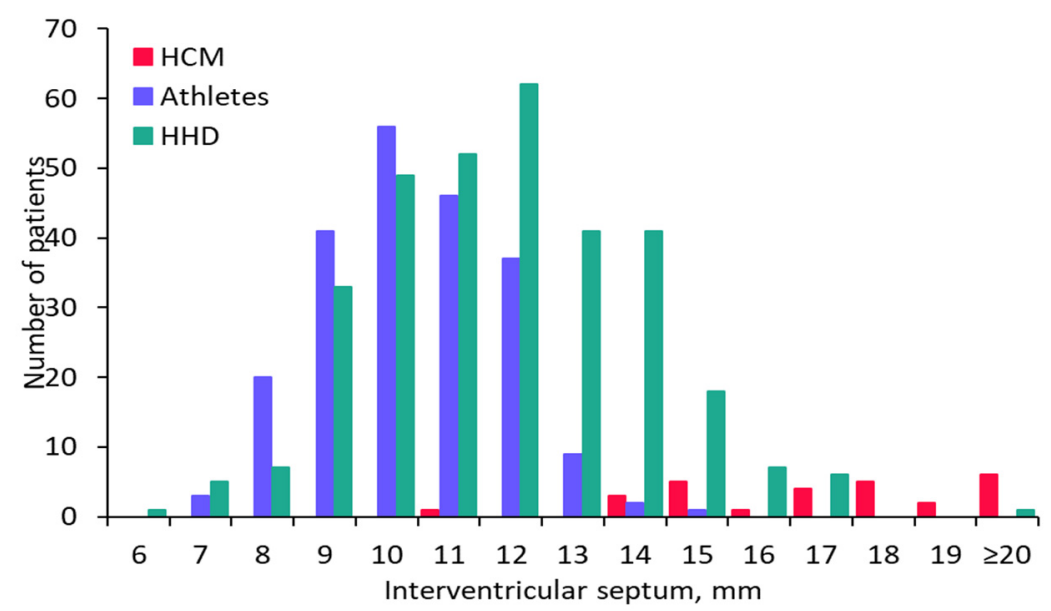

Figure 1. Thickness of the interventricular septum in the three groups. Bar graph showing the thickness of the interventricular septum in millimeters on the $\mathrm{x}$-axis and the corresponding number of patients in each of the three groups on the y-axis. The dashed line separates patients with a thickness of the interventricular septum $\geq 13 \mathrm{~mm}$ from the remaining patients. HCM: hypertrophic cardiomyopathy; HHD: hypertensive heart disease.
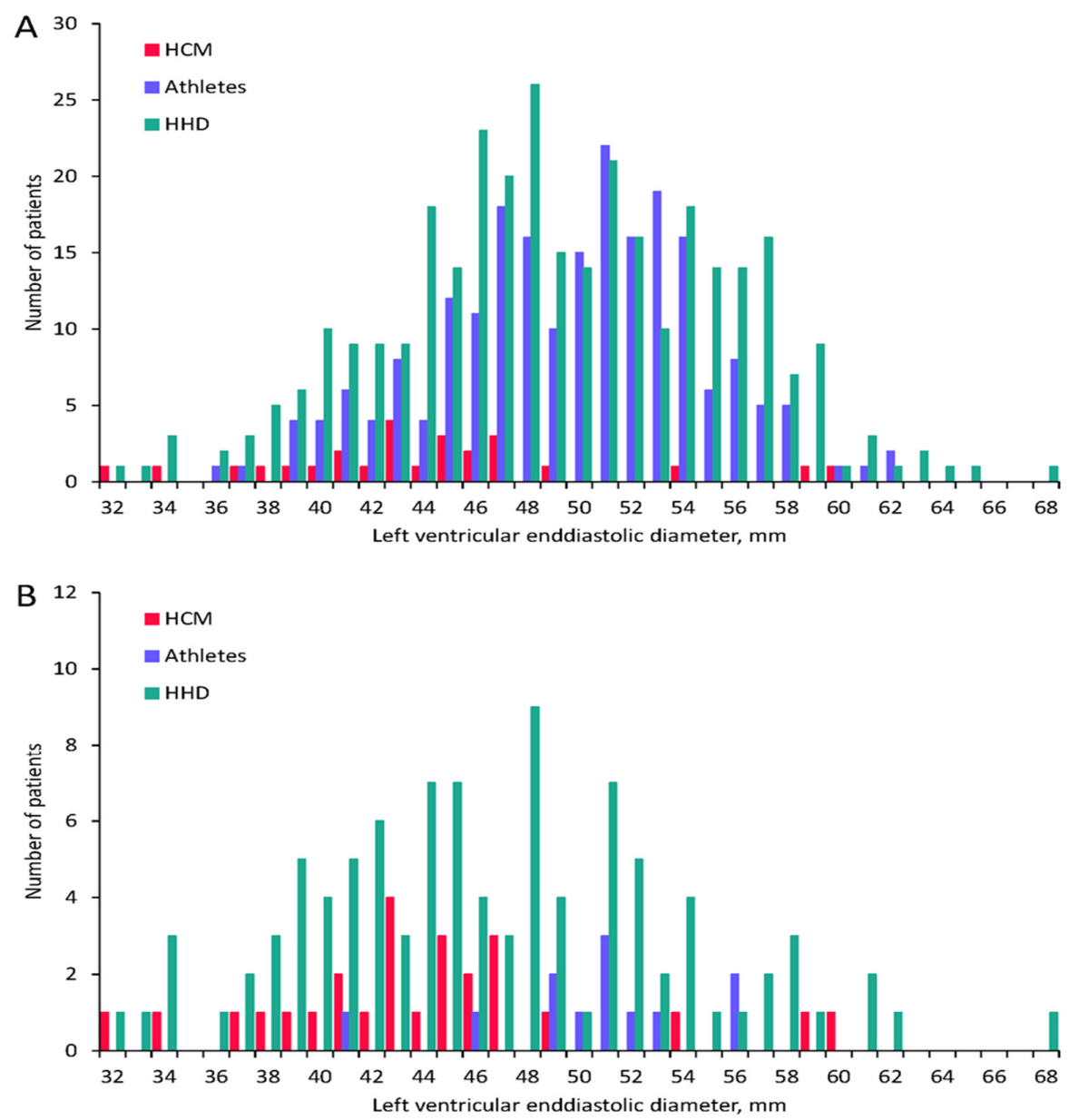

Figure 2. Left ventricular end-diastolic diameter in all patients and in those with septal thickness $>13 \mathrm{~mm}$. Bar graph showing the left ventricular end-diastolic diameter in millimeters on the x-axis and the corresponding number of patients in each of the three groups on the y-axis for all patients (A) and for patients with an interventricular septum thickness $\geq 13 \mathrm{~mm}$ only in the HHD and athlete groups (B). HCM: hypertrophic cardiomyopathy; HHD: hypertensive heart disease. 


\subsection{Electrical Markers of Atrial Cardiomyopathy}

Filtered P-wave duration was significantly longer in HCM patients compared to HHD patients and athletes (Table 1 and Figure 3). Among athletes with IVS13, filtered P-wave duration was significantly shorter compared to those of HCM patients, and there was a trend for shorter filtered P-wave duration in HHD patients with IVS13 compared to those of HCM patients (Table S1). Filtered P-wave duration was significantly associated with both older age and male sex (Table 2). In multivariable regression analysis, filtered P-wave duration remained significantly associated with older age and male sex, as well as presence of HCM. Compared to HCM patients, PACs per hour were significantly more frequent in both HHD patients and HHD patients with IVS13 (Table 1 and Table S1). PACs were rare in athletes. PACs per hour were significantly associated with age and group classification in univariable regression analysis (Table 2). In multivariate regression analysis, only the presence of HHD remained significantly associated with PACs per hour. PR interval was longer in HCM patients compared to those of HHD patients and athletes (Table 1). PR interval was associated with older age and male sex. When corrected for age and sex, the PR interval remained significantly associated with HCM group classification (Table 2).
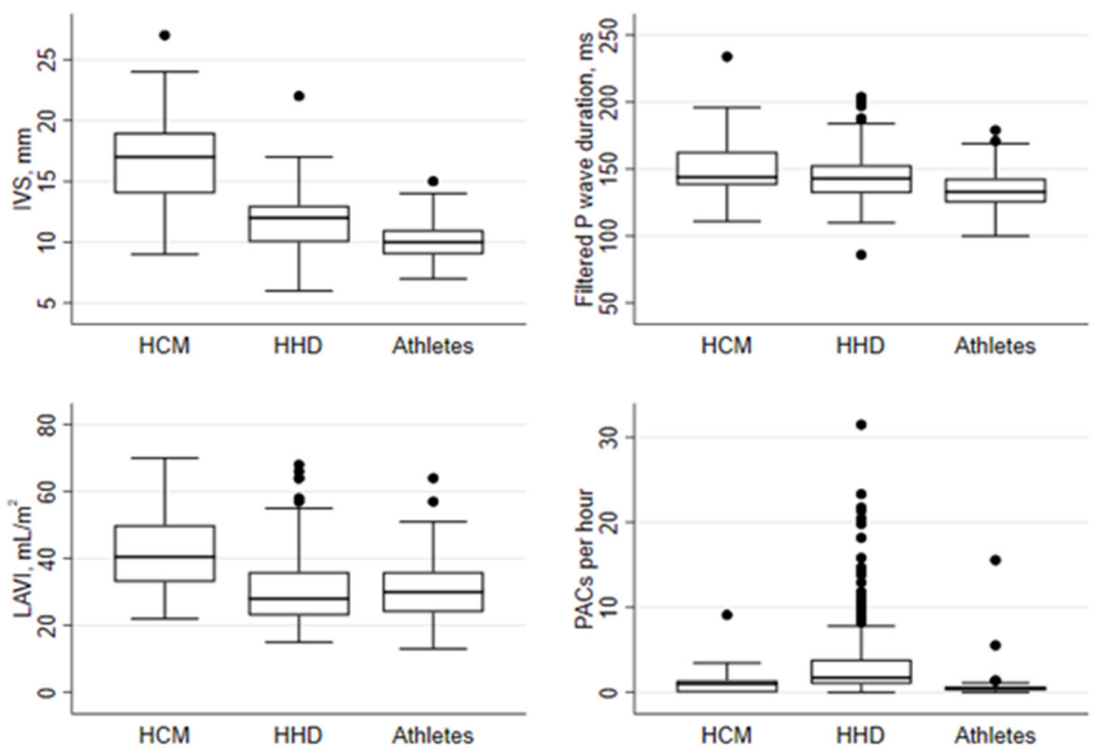

Figure 3. Comparison of the interventricular septal thickness, filtered P-wave duration, LAVI and PACs per hour between the groups. Boxplots for HCM, HHD and athlete groups showing IVS, filtered P-wave duration, LAVI and square-root transformed PACs per hour. IVS: interventricular septum; LAVI: left atrial volume index; PACs: premature atrial complexes.

Table 2. Uni- and multivariable linear regression analysis to assess the effect of age, sex and group assignment on fPWD, PACS count, PR interval, LAVI and BNP.

\begin{tabular}{|c|c|c|c|c|c|c|c|c|}
\hline & Age & $p$ Value & Sex (Female) & $p$ Value & HCM vs. HHD & $p$ Value & HCM vs. Athletes & $p$-Value \\
\hline \multicolumn{9}{|l|}{ Univariable } \\
\hline fPWD, ms & $0.3(0.2$ to 0.4$)$ & $<0.001$ & $-7.7(-10.6$ to -4.7$)$ & $<0.001$ & $-8.8(-18.6$ to 1.0$)$ & 0.079 & $-19.2(-29.0$ to -9.3$)$ & $<0.001$ \\
\hline PACs per hour, sqrt & $0.3(0.3$ to 0.4$)$ & $<0.001$ & $-3.2(-6.4$ to 0.0$)$ & 0.053 & $8.8(5.0$ to 12.6$)$ & $<0.001$ & $-3.9(-7.3$ to -0.5$)$ & 0.026 \\
\hline PR interval, $\mathrm{ms}$ & $0.5(0.3$ to 0.6$)$ & $<0.001$ & $-7.6(-12.6$ to -2.5$)$ & 0.003 & $-13.7(-31.7$ to 4.3$)$ & 0.135 & $-26.3(-44.3$ to -8.2$)$ & 0.004 \\
\hline $\mathrm{LAVI}, \mathrm{mL} / \mathrm{m}^{2}$ & $-0.0(-0.1$ to 0.0$)$ & 0.219 & $0.6(-1.3$ to 2.5$)$ & 0.537 & $-12.8(-18.1$ to -7.4$)$ & $<0.001$ & $-12.5(-18.0$ to -6.9$)$ & $<0.001$ \\
\hline $\mathrm{BNP}, \mathrm{pg} / \mathrm{mL}$ & $0.3(-1.3$ to 1.8$)$ & 0.738 & $15.4(-5.1$ to 35.8$)$ & 0.140 & $-59(-107$ to -11$)$ & 0.017 & - & - \\
\hline \multicolumn{9}{|l|}{ Multivariable } \\
\hline $\mathrm{fPWD}, \mathrm{ms}$ & $0.4(0.2$ to 0.6$)$ & $<0.001$ & $-9.4(-12.0$ to -6.7$)$ & $<0.001$ & $-16.9(-26.3$ to -7.5$)$ & $<0.001$ & $-16.3(-26.2$ to -6.3$)$ & 0.001 \\
\hline PACs per hour, sqrt & $0.0(-0.2$ to 0.3$)$ & 0.804 & $-3.1(-6.2$ to 0.0$)$ & 0.053 & $8.5(0.8$ to 16.1$)$ & 0.029 & $-2.9(-7.8$ to 1.9$)$ & 0.238 \\
\hline PR interval, $\mathrm{ms}$ & $1.1(0.7$ to 1.5$)$ & $<0.001$ & $-10.1(-14.9$ to -5.2$)$ & $<0.001$ & $-38.5(-59.2$ to -17.7$)$ & $<0.001$ & $-18.4(-33.8$ to -3.0$)$ & 0.020 \\
\hline LAVI, $\mathrm{mL} / \mathrm{m}^{2}$ & 0.1 ( -0.1 to 0.2$)$ & 0.395 & $1.0(-0.8$ to 2.9$)$ & 0.253 & $-14.6(-21.0$ to -8.2$)$ & $<0.001$ & $-12.3(-18.0$ to -6.5$)$ & $<0.001$ \\
\hline $\mathrm{BNP}, \mathrm{pg} / \mathrm{mL}$ & $2.9(1.3$ to 4.6$)$ & 0.001 & $18.9(-0.6$ to 38.5$)$ & 0.058 & $-135.2(-190.7$ to -79.8$)$ & $<0.001$ & - & - \\
\hline
\end{tabular}

Shown are average differences/effects with 95\% confidence intervals. BNP: brain natriuretic peptide; fPWD: filtered P-wave duration; HCM: hypertrophic cardiomyopathy; HHD: hypertensive heart disease; LAVI: left atrial volume index; PACs: premature atrial complexes; sqrt: square-root transformed. 


\subsection{Echocardiographic Markers of Atrial Cardiomyopathy}

Left atrial volume index was larger in HCM patients compared to HHD patients and athletes, and also when compared to HHD patients and athletes with IVS13 (Table 1 and Supplementary Table). Age and sex were not associated with LAVI, and in multivariate regression analysis LAVI remained associated with HCM group classification (Table 2).

\subsection{Biochemical Markers of Atrial Cardiomyopathy}

Brain natriuretic peptide was higher in HCM patients compared to both HHD patients and HHD patients with IVS13 (Table 1 and Table S1). High-sensitivity Troponin T and high-sensitivity CRP were not different among HCM and HHD patients. In multivariable regression analysis, brain natriuretic peptide was associated with increasing age and $\mathrm{HCM}$ group classification.

\subsection{Differentiation of HCM Patients from HHD Patients with IVS13}

In ROC analysis, the area under the curve to differentiate HHD patients with IVS13 from HCM patients was 0.863 and 0.733 , respectively, for the IVS thickness and for LAVI (Table 3 and Figure 4). Using LAVI at a cut-off point of $31 \mathrm{~mL} / \mathrm{m}^{2}$ yielded a sensitivity and specificity of $81 \%$ and $57 \%$, respectively, whereas using IVS thickness at a cut-off point of $14 \mathrm{~mm}$ achieved a sensitivity and specificity of $85 \%$ and $72 \%$, respectively. Choosing an interventricular septum thickness at a cut-off point of $16 \mathrm{~mm}$ resulted in a sensitivity and specificity of $52 \%$ and $94 \%$, respectively.

Table 3. ROC curve analyses.

\begin{tabular}{lccccccc}
\hline & Variable & AUC (95\%-CI) & Cut-Off Point & Youden Index & Sensitivity & Specificity & $p$-Value \\
\hline HCM vs. HHD & fPWD, ms & $\begin{array}{c}0.587 \\
(0.461,0.712)\end{array}$ & 139 & 0.177 & 0.704 & 0.474 & 0.176 \\
\hline HCM vs. HHD & LVEDD, mm * & $\begin{array}{c}0.610 \\
(0.494,0.727)\end{array}$ & 48 & 0.285 & 0.846 & 0.439 & 0.088 \\
\hline HCM vs. HHD & IVS, $\mathrm{mm}$ & $\begin{array}{c}0.863 \\
(0.773,0.952)\end{array}$ & 14 & 0.571 & 0.852 & 0.719 & $<0.001$ \\
\hline HCM vs. HHD & LAVI, $\mathrm{mL} / \mathrm{m}^{2}$ & $\begin{array}{c}0.733 \\
(0.633,0.832)\end{array}$ & 31 & 0.382 & 0.815 & 0.568 & $<0.001$ \\
\hline
\end{tabular}

* Indicating HCM, if the value is equal to or lower than the cut-off point, otherwise indicating HHD. fPWD filtered P-wave duration; IVS: interventricular septum thickness; LAVI: left atrial volume index; LVEDD: left ventricular diastolic diameter.

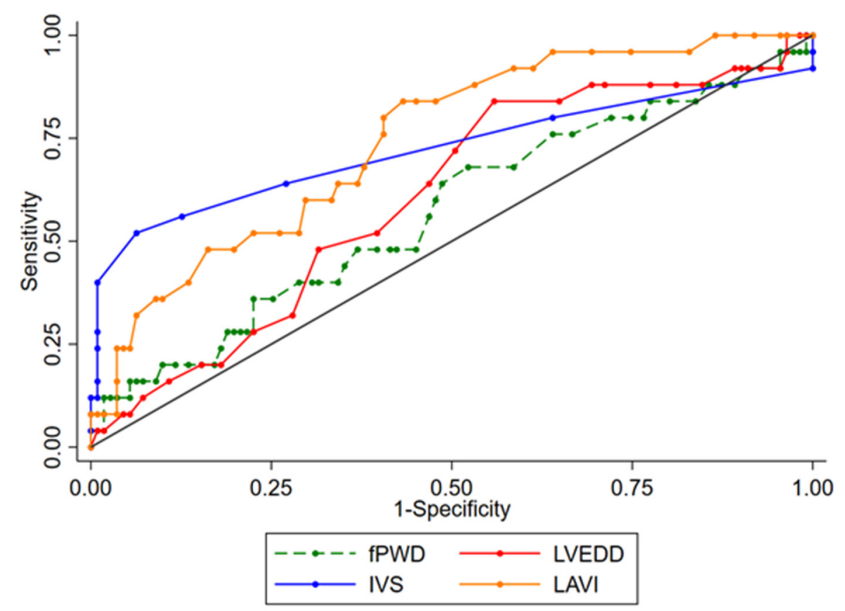

Figure 4. Receiver operating characteristic curves for distinguishing HCM patients from HHD patients with an interventricular septum thickness $\geq 13 \mathrm{~mm}$. FPWD: filtered P-wave duration; IVS: interventricular septum thickness; LAVI: left atrial volume index; LVEDD: left ventricular diastolic diameter. 


\section{Discussion}

The main findings of our study are as follows: (1) among HCM and HHD patients and athletes, electrical and structural remodeling of the atrium as assessed by filtered P-wave duration, PR interval and LAVI is the most advanced in HCM patients; (2) PACs per hour are most frequent in HHD patients; (3) the prevalence of subjects with IVS13 is $6 \%$ in endurance athletes and 35\% in an elderly hypertensive patient population; and (4) LAVI $\geq 31 \mathrm{~mL} / \mathrm{m}^{2}$ has a sensitivity of $81 \%$, and interventricular septum thickness $\geq 16 \mathrm{~mm}$ a specificity of $94 \%$ to differentiate HCM from HHD patients with IVS13.

Compared to the general population, the prevalence of atrial fibrillation is higher in patients with HCM or HHD or in endurance athletes $[13,14]$. Unfavorable atrial remodeling imposed by chronically increased loading conditions is among the most important risk factors for atrial fibrillation. In HCM, increased ventricular mass and impaired diastolic function is a direct consequence of genetically mediated myocardial disease, and in HHD it is the chronically increased afterload that leads to these conditions. Both pathologies result in increased filling pressure and dilation of the left atria. Additionally, myocyte hypertrophy and disarray probably also directly affect the atrial tissue in HCM $[16,17]$. In athletes, chronic volume overload with repetitive episodes of atrial stretching during long-term endurance training is mainly responsible for atrial remodeling [18].

Prolonged P-wave duration, as assessed by SAECG, is a correlate for electric atrial remodeling and probably atrial cardiomyopathy and results from a combination of slowed electrical conduction velocity, suggesting the presence of fibrosis, and atrial dilation [27]. In a general population aged 50 years, the filtered P-wave duration is expected to be about $120 \mathrm{~ms}$, [28] and this is clearly shorter than the $153 \mathrm{~ms}$ observed in our HCM group. A $\mathrm{P}$-wave duration of $146 \mathrm{~ms}$ has been described in patients with HHD and atrial fibrillation, and of $128 \mathrm{~ms}$ in HHD patients without atrial fibrillation [29]. Filtered P-wave duration increases with age and is longer in men [30]. After correcting for age and male sex, P-wave duration was still significantly longer in our HCM group compared to the HHD and athlete groups. In fact, after correction for age and male sex, $\mathrm{P}$-wave duration was on average $16 \mathrm{~ms}$ longer in HCM group compared to the other two groups. Prolonged PR interval is another well-described predictor of incidental atrial fibrillation and is associated with atrial cardiomyopathy [31]. Determinants of PR interval are conduction time through the right atrium, AV node and His-Purkinje system. Vagal tone profoundly affects PR interval, and is most pronounced in athletes. After correction for age and male sex, PR interval was shortest in the HHD group, and, unsurprisingly, longer in athletes. However, the longest PR intervals were found in the HCM group, with intervals on average $39 \mathrm{~ms}$ longer compared to HHD group and $18 \mathrm{~ms}$ longer compared to athletes, which could be explained by the structural changes in the myocytes linked to this genetic disease.

Frequent PACs per hour suggests the presence of a trigger for atrial fibrillation [32]. Interestingly, PACs per hour were most numerous in the HHD group, even after adjustment for age and sex. Athletes on the other hand had a low PAC count. An initial sharp increase in the risk of atrial fibrillation with rising PAC count has been reported, starting already at as few as four to five PACs per hour, ref. [32] as observed in our HCM group.

Indexed left atrial volume was largest in the HCM group, and remained unchanged after correction for age and sex. Increased left atrial volume is an established structural criterion for advanced atrial cardiomyopathy, and is also associated with an increased incidence of atrial fibrillation [33]. On average, LAVI was larger by over $12 \mathrm{~mL} / \mathrm{m}^{2}$ in HCM patients, compared to HHD patients and athletes, in which LAVI was only mildly abnormal. The severely abnormal LAVI in HCM patients reflects high filling pressures due to diastolic dysfunction, and mitral regurgitation following systolic anterior movement of one or both leaflets [34]. To the same end, increased BNP levels in HCM patients also results from abnormal loading conditions, and, after adjustment for age and sex, are increased in HCM compared to HHD patients.

The diagnosis of HCM is based on a wall thickness of $\geq 15 \mathrm{~mm}$ anywhere in the left ventricle in the absence of another cause of hypertrophy. Diagnosis of HCM can be 
difficult in HCM patients and athletes, particularly in the presence of an interventricular septum with a borderline thickness of 1-14 $\mathrm{mm}$. In our cohort of endurance athletes, such borderline interventricular septum thickness was present in $6 \%$ of cases, similar to the rates published in other series [35]. Compared to HCM patients, athletes and HHD patients tend to have a larger left ventricular cavity relative to septum thickness, which was also the case in our study [36]. Mildly dilated atria are a frequent finding in athletes and patients with HHD, whereas atria are more severely dilated in HCM patients [37]. Accordingly, a LAVI $\geq 31 \mathrm{~mL} / \mathrm{m}^{2}$ had a sensitivity of $81 \%$ for distinguishing $\mathrm{HCM}$ patients from patients with HHD and IVS13, whereas an interventricular septum thickness $\geq 16$ mm was highly specific.

The findings of this study should be viewed in light of several limitations. First, there were significant differences in patient characteristics between the three groups studied. Particularly, HCM patients and athletes were more likely to be male and younger than HHD patients. Second, although data was collected prospectively for all three groups by the same investigators and using the same methods, evaluations were performed at varying times, which may have introduced bias. Third, we included patients with an established diagnosis of HCM for this study. These patients tended to have a more advanced phenotype of $\mathrm{HCM}$, and the results may not apply to patients with an inconclusive diagnosis or less advanced phenotype. Finally, the HCM group included a much smaller number of cases as compared to the other two groups. Larger datasets might allow for analysis of more variables affecting atrial remodeling.

\section{Conclusions}

Our findings indicate that electrical and structural remodeling of the atrium is more advanced in HCM patients compared to HHD patients and athletes. These findings might be attributed to the complex pathophysiology of HCM with the involvement of a genetic factor and a remodeling secondary to reduced LV compliance.

Supplementary Materials: The following supporting information can be downloaded at: https: //www.mdpi.com/article/10.3390/jcm11051316/s1, Table S1: Clinical characteristics of patient subgroups with interventricular septum thickness $\geq 13 \mathrm{mms}$ in HHD group and athletes.

Author Contributions: Data curation, H.S., S.R. and N.N.; Formal analysis, H.S., S.R. and M.B.; Funding acquisition, L.R.; Investigation, H.S., S.R., M.W. and L.R.; Methodology, H.S., M.B., N.B., M.W. and L.R.; Project administration, H.S.; Resources, H.S. and L.R.; Supervision, L.R.; Visualization, H.S., B.A. and L.R.; Writing — original draft, H.S. and A.M.; Writing—review \& editing, H.S., B.A., A.H., S.d.M., N.B., N.N., E.G., E.E., A.L., J.S., F.N., H.T., S.H.B., T.R., M.W. and L.R. All authors have read and agreed to the published version of the manuscript.

Funding: The STAR-FIB study program was supported by a grant from the Swiss National Science Foundation (Grant number 32003B_156292) and by the Swiss Heart Foundation.

Institutional Review Board Statement: The Cantonal Ethics Committee of Bern, Switzerland, approved the study protocol.

Informed Consent Statement: All participants provided written informed consent.

Data Availability Statement: Individual patient data included in this study can not be provided due to restrictions set by the Ethics Committee.

Conflicts of Interest: The authors declare no conflict of interest.

Disclosures: A. Haeberlin: Travel/educational grants from Medtronic and Philips/Spectranetics. Co-founder and head of Act-Inno, a cardiovascular device testing company. Research grants from the Swiss National Science Foundation, the Swiss Heart Foundation, the Swiss Heart Rhythm Foundation, the Swiss Pacemaker Foundation, the Hasler Foundation, the Velux Foundation, Novartis and the sitem-insel Support Funds, all for work outside the study submitted. Consultant/advisor for DiNAQOR and Biotronik for work outside the study submitted. H. Tanner: Travel grant from Abbott, educational grant from Biosense WebsterT. Reichlin reports research grants from the GoldschmidtJacobson Foundation, the Swiss National Science Foundation, the Swiss Heart Foundation and the 
sitem-insel Support Funds, all for work outside the study submitted; reports consulting, advisory boards, speaker, and travel support from Abbott/SJM, AstraZeneca, Brahms, Bayer, Biosense Webster, Biotronik, Boston Scientific, Daiichi Sankyo, Medtronic, Pfizer-BMS and Roche, all for work outside the submitted study; and reports support for his institution's fellowship program from Abbott/SJM, Biosense Webster, Biotronik, Boston-Scientific and Medtronic for work outside the submitted study. L. Roten: has received consulting honoraria from Abbott/SJM and Medtronic.

\section{References}

1. Elliott, P.M.; Anastasakis, A.; Borger, M.A.; Borggrefe, M.; Cecchi, F.; Charron, P.; Hagege, A.A.; Lafont, A.; Limongelli, G.; Mahrholdt, H.; et al. 2014 Esc Guidelines on Diagnosis and Management of Hypertrophic Cardiomyopathy: The Task Force for the Diagnosis and Management of Hypertrophic Cardiomyopathy of the European Society of Cardiology (Esc). Eur. Heart J. 2014, 35, 2733-2779. [PubMed]

2. Brito, D.; Miltenberger-Miltenyi, G.; Vale Pereira, S.; Silva, D.; Diogo, A.N.; Madeira, H. Sarcomeric Hypertrophic Cardiomyopathy: Genetic Profile in a Portuguese Population. Rev. Port. Cardiol. 2012, 31, 577-587. [CrossRef] [PubMed]

3. Ingles, J.; Burns, C.; Barratt, A.; Semsarian, C.; Couns, G.D.G. Application of Genetic Testing in Hypertrophic Cardiomyopathy for Preclinical Disease Detection. Circ. Cardiovasc. Genet. 2015, 8, 852-859. [CrossRef] [PubMed]

4. Kassem, H.S.; Azer, R.S.; Saber-Ayad, M.; Moharem-Elgamal, S.; Magdy, G.; Elguindy, A.; Cecchi, F.; Olivotto, I.; Yacoub, M.H. Early Results of Sarcomeric Gene Screening from the Egyptian National BA-HCM Program. J. Cardiovasc. Transl. Res. 2012, 6, 65-80. [CrossRef] [PubMed]

5. Maron, B.J.; Casey, S.A.; Poliac, L.C.; Gohman, T.E.; Almquist, A.K.; Aeppli, D.M. Clinical Course of Hypertrophic Cardiomyopathy in a Regional United States Cohort. JAMA J. Am. Med. Assoc. 1999, 281, 650-655. [CrossRef]

6. Morita, H.; Rehm, H.L.; Menesses, A.; McDonough, B.; Roberts, A.E.; Kucherlapati, R.; Towbin, J.A.; Seidman, J.; Seidman, C.E. Shared Genetic Causes of Cardiac Hypertrophy in Children and Adults. N. Engl. J. Med. 2008, 358, 1899-1908. [CrossRef]

7. Van Driest, S.L.; Ommen, S.R.; Tajik, A.J.; Gersh, B.J.; Ackerman, M.J. Sarcomeric genotyping in hypertrophic cardiomyopathy. Mayo Clin. Proc. 2005, 80, 463-469. [CrossRef]

8. Semsarian, C.; Ingles, J.; Maron, M.S.; Maron, B.J. New Perspectives on the Prevalence of Hypertrophic Cardiomyopathy. J. Am. Coll. Cardiol. 2015, 65, 1249-1254. [CrossRef]

9. McLeod, C.J.; Ackerman, M.J.; Nishimura, R.A.; Tajik, A.J.; Gersh, B.J.; Ommen, S.R. Outcome of Patients With Hypertrophic Cardiomyopathy and a Normal Electrocardiogram. J. Am. Coll. Cardiol. 2009, 54, 229-233. [CrossRef]

10. Rowin, E.J.; Maron, B.J.; Appelbaum, E.; Link, M.S.; Gibson, C.M.; Lesser, J.R.; Haas, T.S.; Udelson, J.E.; Manning, W.J.; Maron, M.S. Significance of False Negative Electrocardiograms in Preparticipation Screening of Athletes for Hypertrophic Cardiomyopathy. Am. J. Cardiol. 2012, 110, 1027-1032. [CrossRef]

11. Shirani, J.; Pick, R.; Roberts, W.C.; Maron, B.J. Morphology and significance of the left ventricular collagen network in young patients with hypertrophic cardiomyopathy and sudden cardiac death. J. Am. Coll. Cardiol. 2000, 35, 36-44. [CrossRef]

12. Charron, P.; Forissier, J.; Amara, M.; Dubourg, O.; Desnos, M.; Bouhour, J.-B.; Isnard, R.; Hagege, A.; Béna1che, A.; Richard, P.; et al. Accuracy of European diagnostic criteria for familial hypertrophic cardiomyopathy in a genotyped population. Int. J. Cardiol. 2003, 90, 33-38. [CrossRef]

13. Guttmann, O.P.; Rahman, M.S.; O'Mahony, C.; Anastasakis, A.; Elliott, P.M. Atrial fibrillation and thromboembolism in patients with hypertrophic cardiomyopathy: Systematic review. Heart 2013, 100, 465-472. [CrossRef] [PubMed]

14. Kirchhof, P.; Lip, G.Y.; Van Gelder, I.C.; Bax, J.; Hylek, E.; Kaab, S.; Schotten, U.; Wegscheider, K.; Boriani, G.; Brandes, A.; et al. Comprehensive risk reduction in patients with atrial fibrillation: Emerging diagnostic and therapeutic options-A report from the 3rd Atrial Fibrillation Competence NETwork/European Heart Rhythm Association consensus conference. Europace 2012, 14, 8-27. [CrossRef] [PubMed]

15. Goette, A.; Kalman, J.M.; Aguinaga, L.; Akar, J.; Cabrera, J.A.; Chen, S.A.; Chugh, S.S.; Corradi, D.; D’Avila, A.; Dobrev, D.; et al. Ehra/Hrs/Aphrs/Solaece Expert Consensus on Atrial Cardiomyopathies: Definition, Characterization, and Clinical Implication. Europace 2016, 18, 1455-1490. [CrossRef]

16. Farhad, H.; Seidelmann, S.B.; Vigneault, D.; Abbasi, S.A.; Yang, E.; Day, S.M.; Colan, S.D.; Russell, M.W.; Towbin, J.; Sherrid, M.V.; et al. Left Atrial structure and function in hypertrophic cardiomyopathy sarcomere mutation carriers with and without left ventricular hypertrophy. J. Cardiovasc. Magn. Reson. 2017, 19, 107. [CrossRef]

17. Latif, S.R.; Nguyen, V.Q.; Peters, D.C.; Soufer, A.; Henry, M.L.; Grunseich, K.; Testani, J.; Hur, D.; Huber, S.; Mojibian, H.; et al. Left atrial fibrosis correlates with extent of left ventricular myocardial delayed enhancement and left ventricular strain in hypertrophic cardiomyopathy. Int. J. Cardiovasc. Imaging 2019, 35, 1309-1318. [CrossRef]

18. Wilhelm, M.; Nuoffer, J.-M.; Schmid, J.-P.; Wilhelm, I.; Saner, H. Comparison of Pro-Atrial Natriuretic Peptide and Atrial Remodeling in Marathon Versus Non-Marathon Runners. Am. J. Cardiol. 2012, 109, 1060-1065. [CrossRef]

19. Lang, R.M.; Badano, L.P.; Mor-Avi, V.; Afilalo, J.; Armstrong, A.; Ernande, L.; Flachskampf, F.A.; Foster, E.; Goldstein, S.A.; Kuznetsova, T.; et al. Recommendations for Cardiac Chamber Quantification by Echocardiography in Adults: An Update from the American Society of Echocardiography and the European Association of Cardiovascular Imaging. J. Am. Soc. Echocardiogr. 2015, 28, 1-39.e14. [CrossRef] 
20. Nozica, N.; Lam, A.; Goulouti, E.; Elchinova, E.; Spirito, A.; Branca, M.; Servatius, H.; Noti, F.; Seiler, J.; Baldinger, S.H.; et al. The SilenT AtRial FIBrillation (STAR-FIB) study programme-Design and rationale. Swiss Med. Wkly. 2021, 151, w20421. [CrossRef]

21. Roten, L.; Goulouti, E.; Lam, A.; Elchinova, E.; Nozica, N.; Spirito, A.; Wittmer, S.; Branca, M.; Servatius, H.; Noti, F.; et al. Age and Sex Specific Prevalence of Clinical and Screen-Detected Atrial Fibrillation in Hospitalized Patients. J. Clin. Med. 2021, $10,4871$. [CrossRef] [PubMed]

22. Wilhelm, M.; Roten, L.; Tanner, H.; Schmid, J.-P.; Wilhelm, I.; Saner, H. Long-Term Cardiac Remodeling and Arrhythmias in Nonelite Marathon Runners. Am. J. Cardiol. 2012, 110, 129-135. [CrossRef] [PubMed]

23. Brugger, N.; Krause, R.; Carlen, F.; Rimensberger, C.; Hille, R.; Steck, H.; Wilhelm, M.; Seiler, C. Effect of lifetime endurance training on left atrial mechanical function and on the risk of atrial fibrillation. Int. J. Cardiol. 2014, 170, 419-425. [CrossRef] [PubMed]

24. Darbar, D.; Jahangir, A.; Hammill, S.C.; Gersh, B.J. P Wave Signal-Averaged Electrocardiography to Identify Risk for Atrial Fibrillation. Pacing Clin. Electrophysiol. 2002, 25, 1447-1453. [CrossRef]

25. Dhala, A.; Underwood, D.; Leman, R.; Madu, E.; Baugh, D.; Ozawa, Y.; Kasamaki, Y.; Xue, Q.; Reddy, S. Signal-Averaged P-Wave Analysis of Normal Controls and Patients with Paroxysmal Atrial Fibrillation: A Study in Gender Differences, Age Dependence, and Reproducibility. Clin. Cardiol. 2002, 25, 525-531. [CrossRef] [PubMed]

26. Evangelista, A.; Flachskampf, F.; Lancellotti, P.; Badano, L.; Aguilar, R.; Monaghan, M.; Zamorano, J.; Nihoyannopoulos, P.; on behalf of the European Association of Echocardiography. European Association of Echocardiography recommendations for standardization of performance, digital storage and reporting of echocardiographic studies. Eur. J. Echocardiogr. 2008, 9, 438-448. [CrossRef]

27. Magnani, J.W.; Williamson, M.A.; Ellinor, P.T.; Monahan, K.M.; Benjamin, E.J. P Wave Indices: Current Status and Future Directions in Epidemiology, Clinical, and Research Applications. Circ. Arrhythm. Electrophysiol. 2009, 2, 72-79. [CrossRef]

28. Kornej, J.; Magnani, J.W.; Preis, S.R.; Soliman, E.Z.; Trinquart, L.; Ko, D.; Benjamin, E.J.; Lin, H. P-wave signal-averaged electrocardiography: Reference values, clinical correlates, and heritability in the Framingham Heart Study. Heart Rhythm 2021, 18, 1500-1507. [CrossRef]

29. Aytemir, K.; Amasyali, B.; Abali, G.; Kose, S.; Kilic, A.; Onalan, O.; Tokgozoglu, L.; Kabakci, G.; Ozkutlu, H.; Nazli, N.; et al. The signal-averaged P-wave duration is longer in hypertensive patients with history of paroxysmal atrial fibrillation as compared to those without. Int. J. Cardiol. 2005, 103, 37-40. [CrossRef]

30. Militaru, C.; Donoiu, I.; Ionescu, D.-D. P Wave Signal-Averaged ECG in Normal Population and in Patients with Converted Atrial Fibrillation. Ann. Noninvasive Electrocardiol. 2011, 16, 351-356. [CrossRef]

31. Schnabel, R.B.; Sullivan, L.; Levy, D.; Pencina, M.J.; Massaro, J.; D'Agostino, R.B.; Newton-Cheh, C.; Yamamoto, J.F.; Magnani, J.W.; Tadros, T.M.; et al. Development of a risk score for atrial fibrillation (Framingham Heart Study): A community-based cohort study. Lancet 2009, 373, 739-745. [CrossRef]

32. Dewland, T.A.; Vittinghoff, E.; Mandyam, M.C.; Heckbert, S.R.; Siscovick, D.S.; Stein, P.K.; Psaty, B.M.; Sotoodehnia, N.; Gottdiener, J.S.; Marcus, G.M. Atrial Ectopy as a Predictor of Incident Atrial Fibrillation: A Cohort Study. Ann. Intern. Med. 2013, 159, 721-728. [CrossRef] [PubMed]

33. Schaaf, M.; Andre, P.; Altman, M.; Maucort-Boulch, D.; Placide, J.; Chevalier, P.; Bergerot, C.; Thibault, H. Left atrial remodelling assessed by 2D and 3D echocardiography identifies paroxysmal atrial fibrillation. Eur. Heart J. Cardiovasc. Imaging 2017, 18, 46-53. [CrossRef] [PubMed]

34. Finocchiaro, G.; Sheikh, N.; Biagini, E.; Papadakis, M.; Maurizi, N.; Sinagra, G.; Pelliccia, A.; Rapezzi, C.; Sharma, S.; Olivotto, I. The electrocardiogram in the diagnosis and management of patients with hypertrophic cardiomyopathy. Heart Rhythm 2020, 17, 142-151. [CrossRef]

35. Basavarajaiah, S.; Wilson, M.; Whyte, G.; Shah, A.; McKenna, W.; Sharma, S. Prevalence of Hypertrophic Cardiomyopathy in Highly Trained Athletes: Relevance to Pre-Participation Screening. J. Am. Coll. Cardiol. 2008, 51, 1033-1039. [CrossRef]

36. Caselli, S.; Maron, M.S.; Urbano-Moral, J.A.; Pandian, N.G.; Maron, B.J.; Pelliccia, A. Differentiating Left Ventricular Hypertrophy in Athletes from That in Patients with Hypertrophic Cardiomyopathy. Am. J. Cardiol. 2014, 114, 1383-1389. [CrossRef]

37. Cheng, T.O. Hypertrophic Cardiomyopathy Vs Athlete's Heart. Int. J. Cardiol. 2009, 131, 151-155. [CrossRef] 